\title{
AS CORRIDAS IMERSIVAS \\ E O DESIGN EMOCIONAL
}

Para iniciar a análise das corridas, éimportante destacar uma simplificação de Norman (2012, p. 59) dos conceitos do design emocional:

» Design visceral > aparência

» Design comportamental > prazer e efetividade de uso

» Design reflexivo > autoimagem, satisfação pessoal, lembrança

Partindo dos conceitos descritos anteriormente, a análise das três corridas foi feita destacando-se o nível de design emocional mais evidente em cada uma delas, como a direção de arte dos ambientes e da cenografia que as compõem foi projetada de modo a suscitar emoções positivas em seus participantes.

Optou-se por mostrar cada nível em uma corrida de modo a demonstrar de que maneira a direção de arte de cada evento buscou aplicar soluções do design emocional enaltecendo emoções diferentes nos corredores. Como afirma Norman (2012, p. 59), "qualquer experiência real envolve todos os três níveis: um único nível é raro na prática e, se por ventura existir, é mais provável que venha do nível reflexivo do que do comportamental ou do visceral".

Sob a ótica do design visceral, analisaremos a Star Wars Run 2016; para o design comportamental, a Marvel Run: Desafio Vingadores 2015; e, para o design reflexivo, a Disney Princess Magical Run 2017. 


\subsection{Visceral: Star Wars Run 2016}

A Star Wars Run 2016 ocorreu na noite de 29 de outubro de 2016 e teve como temática de imersão o filme Rogue One: uma história Star Wars ${ }^{1}$. Em sua $3^{a}$ edição e com percurso de 7 km, o evento reuniu cerca de 6 mil pessoas no ponto de largada e chegada, no Memorial da América Latina, Barra Funda, São Paulo. As empresas responsáveis pela organização do evento foram a Disney, a Norte Marketing Esportivo e a Corpore.

\subsubsection{Cores, formas, sons e texturas}

As paletas de cores que compunham os materiais e a cenografia da Star Wars Run 2016 eram primordialmente contrastantes e saturadas, como laranja, vermelho, azul e amarelo aplicadas sobre fundo preto. O background preto remetia ao universo espacial do filme e ao caráter obscuro de certos personagens, além de contrastar com as cores vibrantes das explosões, dos lasers e dos sabres de luz.
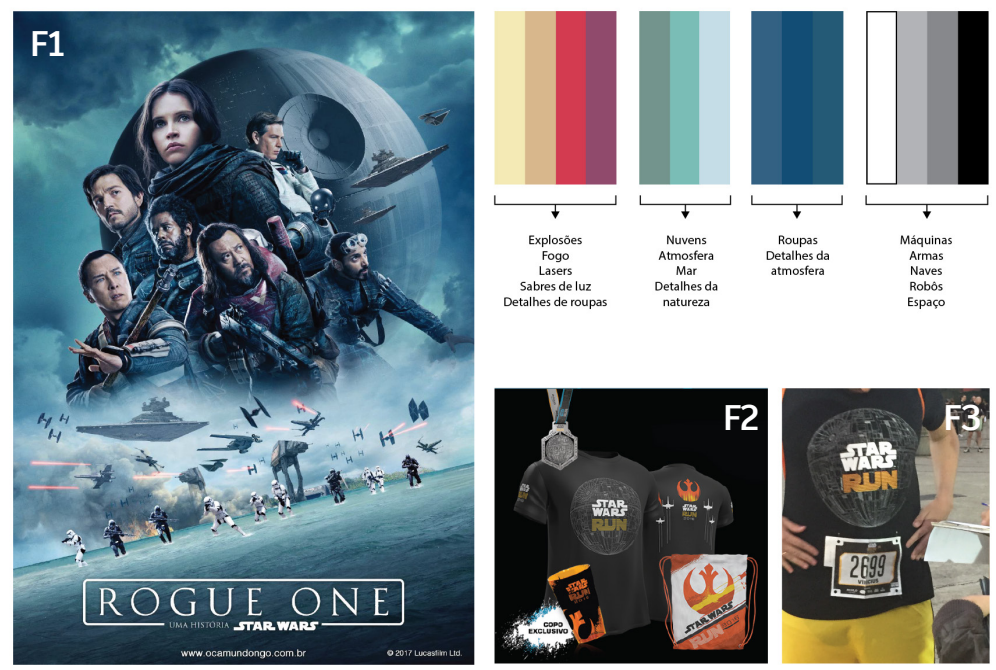

Figura 3 - Diagrama de cores do pôster do filme Rogue One à esquerda e sua aplicação no kit de participação da Star Wars Run 2016 à direita. Fontes: F1: 0 Camundongo. F2: Star Wars Run 2016. F3: acervo do autor.

\footnotetext{
${ }^{1}$ Rogue One: uma história Star Wars (Rogue One: A Star Wars Story) é uma produção norteamericana de 2016 do gênero ação/ficção científica, dirigida por Gareth Edwards e escrito por Chris Weitz. Faz parte de uma série de spin-offs produzidos pela Disney com base na franquia Star Wars, criada por George Lucas.
} 
A partir da paleta de cores apresentada na Figura 3, nota-se que o kit de participação tinha por objetivo retratar a atmosfera densa e sombria com cores neutras que representassem máquinas, naves, armas e o espaço do filme aplicados na camiseta, no copo e na medalha, em contraste com os tons vibrantes de amarelo, vermelho, laranja e azul dos lasers, dos sabres de luz e das explosões aplicados na mochila e em detalhes da camiseta, do copo e do número de inscrição. A visceralidade das cores imergia o corredor em um ambiente espacial lúdico criado para gerar sensações de empolgação, ansiedade e apreensão durante o evento.

Essas sensações, embora negativas do ponto de vista do design emocional visceral, eram pautadas no caráter reflexivo positivo da obra cinematográfica, em sua contextualização de mistério e na dicotomia de luta do bem contra o mal.

Pode-se notar o aspecto visceral nas formas de diversos elementos cenográficos produzidos pela direção de arte do evento (Figuras A.1 e A.2), que buscou utilizar grandes círculos e formatos arredondados de planetas em contraste com as formas pontiagudas e retilíneas das armas e das espaçonaves. Seu intuito era remeter a aspectos tecnológicos, aproximando o corredor da ficção científica explorada no filme.

Outro ponto visceral trabalhado foi a utilização de texturas de aspecto rústico (sprays) aplicadas nos materiais de divulgação (Figura A.11), no kit (Figura 3) e em um painel (Figura 4) pintado ao vivo em estêncil pela artista plástica Simone Siss, com imagens relativas ao universo Star Wars e ao filme Rogue One, usando cores vibrantes e fluorescentes: laranja, amarelo, verde, rosa, prata, dourado e branco. 


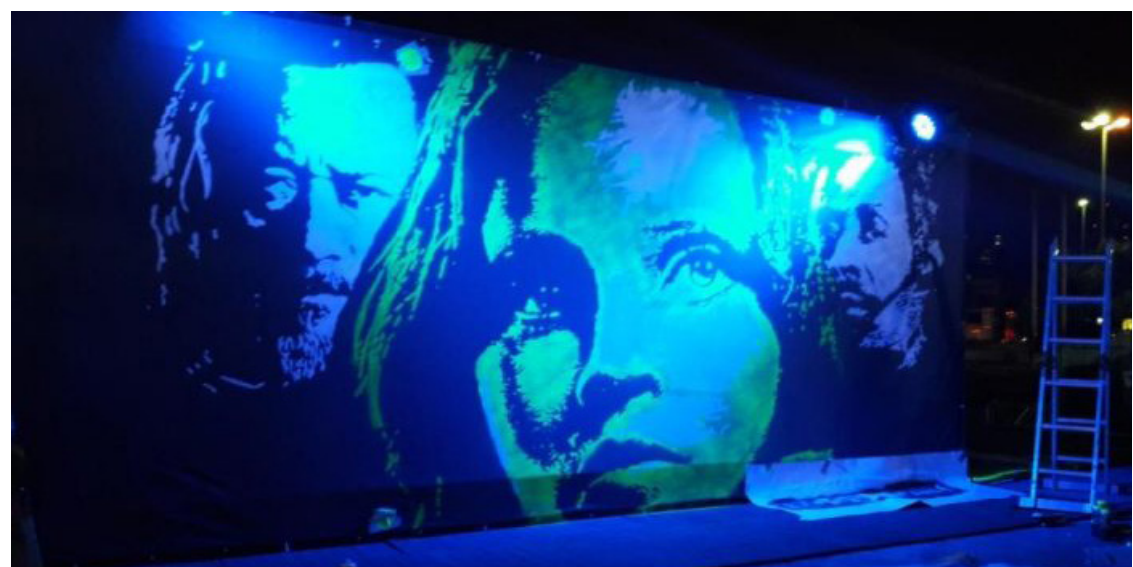

Figura 4 - Painel em processo de pintura com personagens do filme Rogue One na Star Wars Run. Fonte: Miyazato; Franco; Battaglia, 2016.

O design visceral também foi trabalhado nos grandes totens de interação com cenas do filme (Figura 5) e no palco de premiação, que possuía um telão onde era apresentado o trailer do filme, emitindo luzes e soltando fumaça (Figura A.6).

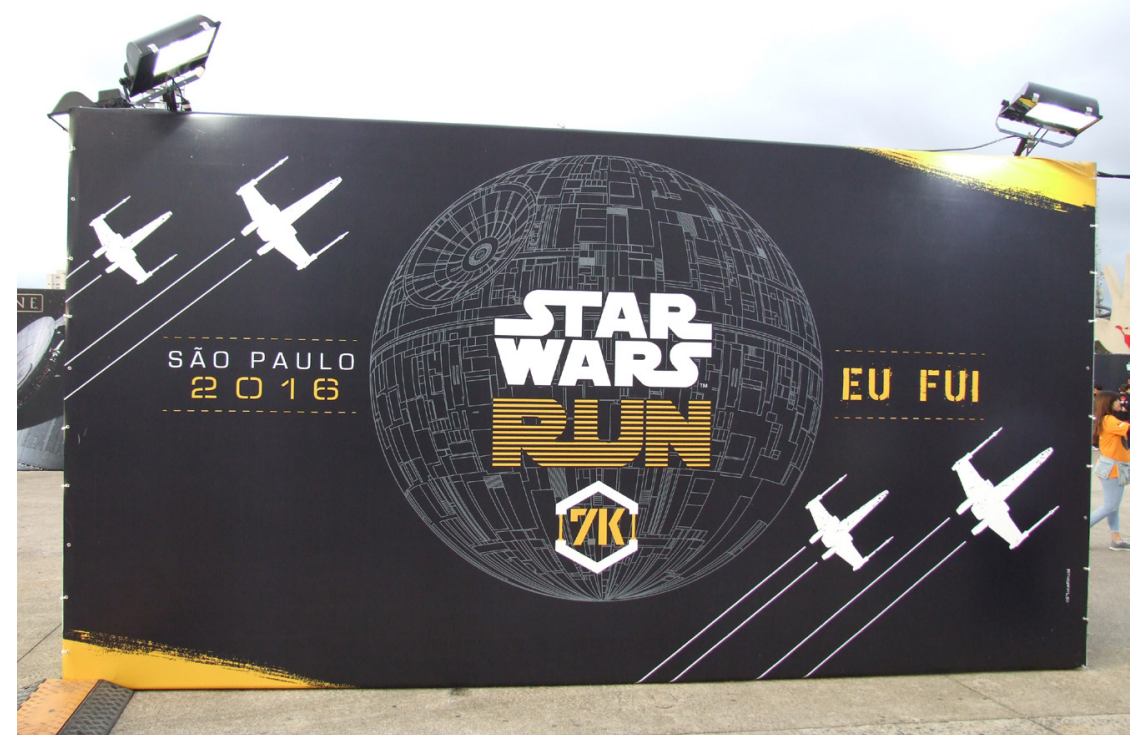

Figura 5 - Um dos totens de interação colocados na arena da Star Wars Run 2016. Fonte: acervo do autor. 
Para reunir os corredores em uma missão em que os rebeldes combateriam as forças terriveis do Império, tal qual acontece no filme, o contraste "bem/mal" e "claro/escuro" norteou a direção de arte em todos os elementos da corrida: cores, formas geométricas, iluminação e demais materiais dispostos na arena.

Pudemos identificar como o trabalho de formas, texturas e cores contrastantes, saturadas e vibrantes, os grandes totens espalhados pelo ambiente, a produção sonora, que reproduzia sons de espaçonaves, tiros e explosões, e o movimento intenso de luzes e efeitos visuais, como fumaça e lasers, criaram um ambiente de forte apelo visual e cumpriram o importante papel de relacionar a temática do filme com a cenografia construída para a corrida. Todos esses elementos foram aplicados de modo a enaltecer sensações viscerais antagônicas como alegria/ medo apreensão/ empolgação por parte do público, com o intuito de suscitar emoções positivas em um ambiente espacial sombrio e denso, próprio da temática da franquia.

\subsection{Comportamental: Marvel Run: Desafio Vingadores 2015}

A Marvel Run: Desafio Vingadores 2015 aconteceu na manhã do dia 26 de abril de 2015, na região próxima ao Pacaembu, em São Paulo, com largada e chegada na praça Charles Miller. Mais de 8 mil pessoas participaram da primeira edição da corrida, que tinha um percurso único de $7 \mathrm{~km}$ que poderia ser percorrido individualmente ou em grupos de seis atletas que, juntos, completariam $42 \mathrm{~km}$. O evento foi organizado e realizado pela Corpore.

A temática imersiva dessa corrida era a do grupo de super-heróis Vingadores da Marvel, empresa que utilizou o evento como ferramenta de marketing para a divulgação do filme Vingadores: Era de Ultron².

Como mencionamos, o nível comportamental diz respeito à funcionalidade e à usabilidade, que, aplicadas ao design, estão atreladas ao prazer e à efetividade de uso de determinado projeto. Nesse sentido, o aspecto primordial de uma corrida de rua é a sua organização para o ato de correr. Ou seja, a imersão do design visceral passa a ter menor relevância e a prática do pedestrianismo durante o evento se sobressai.

\footnotetext{
${ }^{2}$ Vingadores: Era de Ultron (Avengers: Age of Ultron) é uma produção norte-americana de 2015 do gênero ação/ficção científica, dirigida e roteirizada por Joss Whedon, produzida pela Marvel Studios e distribuída pela Disney. Faz parte da sequência do filme Os Vingadores, criado por Stan Lee.
} 


\subsubsection{Percurso e sinalização}

No design comportamental, é interessante observar de que maneira a corrida é organizada pensando na experiência do participante, em seu percurso e na sinalização para que ele possa realizar a prova de maneira satisfatória, confortável e fluida.

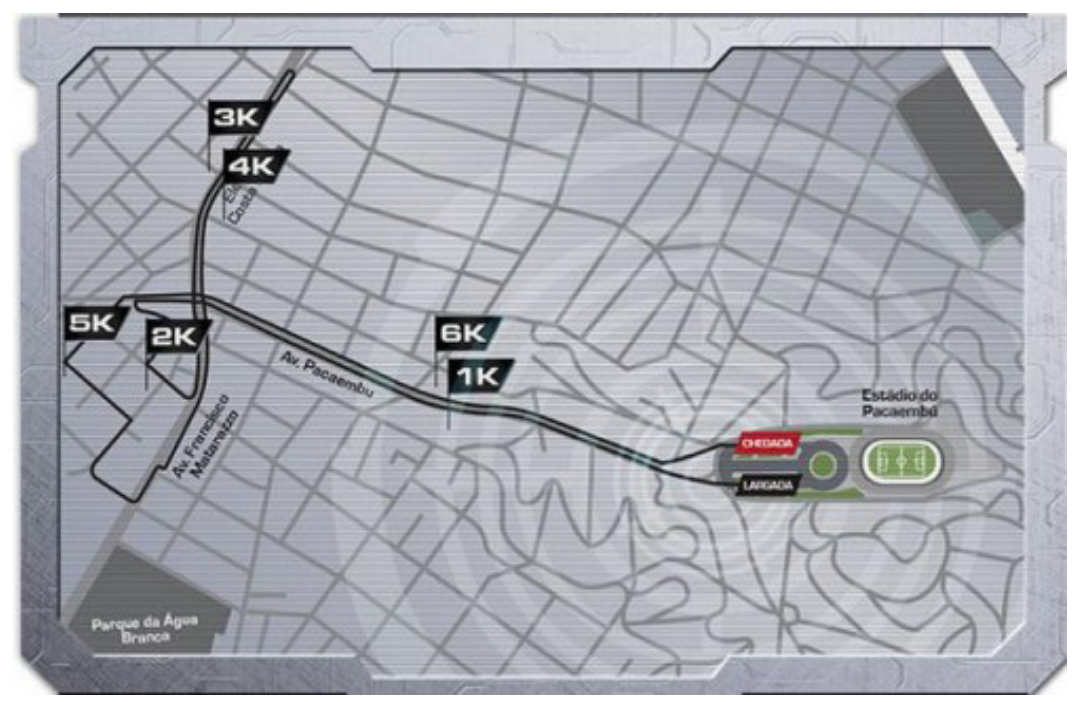

Figura 6 - Mapa do percurso da Marvel Run: Desafio Vingadores 2015. Fonte: Rodrigues, 2015.

O mapa da Figura 6 mostra o percurso da Marvel Run, que foi projetado para iniciar e terminar na Praça Charles Miller, o que, do ponto de vista comportamental, traz segurança e conforto ao corredor, já que ele não precisa realizar nenhum deslocamento após o término da prova.

O participante Eduardo Brinco (BLOG CORRIDA DE RUA, 2015) descreve alguns pontos funcionais que proporcionaram a sensação de conforto e domínio sobre a prova.

O trajeto de São Paulo não é fácil, cheio de subidas e descidas, o que cansa bastante para quem não está preparado, mas estava super sinalizado, além disso contava com o staff motivando os "heróis" a completarem suas provas com coragem e bravura. Os quatro pontos de hidratação tinham mini garrafinhas de água temática, com imagem e figurinha dos Vingadores, e com bico dosador. 
Dois pontos relevantes ressaltados por ele foram a disponibilização de pontos de hidratação a cada 1,5 km e a sinalização da prova. Os pontos de hidratação propiciam o conforto necessário para os corredores desempenharem bem a prova, já a sinalização engloba não só o mapa do percurso, mas também as marcações de quilometragem feitas com totens de sinalização indicando a passagem quilômetro a quilômetro. Essa marcação possuía tipografia clara e auxiliava os participantes a identificar a distância já percorrida e o percurso restante até a chegada.

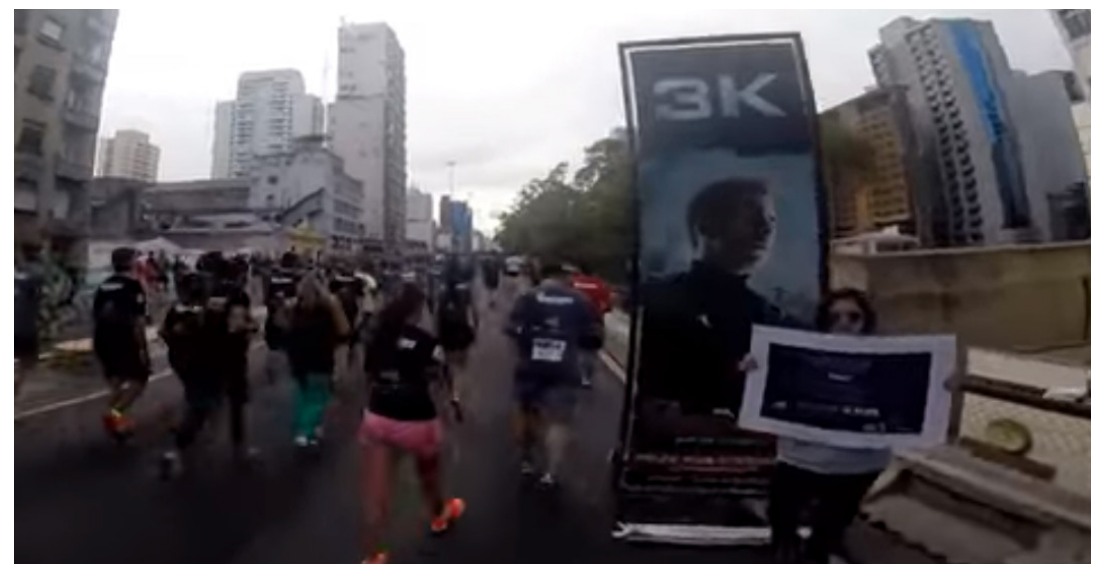

Figura 7 - No canto direito, um dos totens de sinalização de quilometragem da Marvel Run: Desafio Vingadores 2015. Fonte: CEDUPIN MARKETING, 2015.

Conforme pesquisa realizada pelo portal EU ATLETA (2017), um dos itens que mais incomoda um corredor é "a lata de sardinha na largada", com 244 votos. Ou seja, o local onde acontece o momento mais aguardado pelos corredores fica extremamente lotado, inviabilizando o bom desenvolvimento da largada.

A direção de arte da Marvel Run buscou solucionar esse problema utilizando a própria temática imersiva do evento, separando os participantes em baterias classificadas por cada um dos super-heróis que compõem o grupo dos Vingadores: a largada às 7 horas era composta pelos corredores com as camisetas dos heróis Tony Stark (Homem de Ferro) e Capitão América. Logo após, na largada das 7h15, partiram os corredores com as camisetas de Hulk e Viúva Negra. Por fim, na largada das 7h30, os corredores com as camisetas de Thor e Gavião Arqueiro. 


\section{CRUZE A LINHA DE CHEGADA}

COMO UM HERÓI!

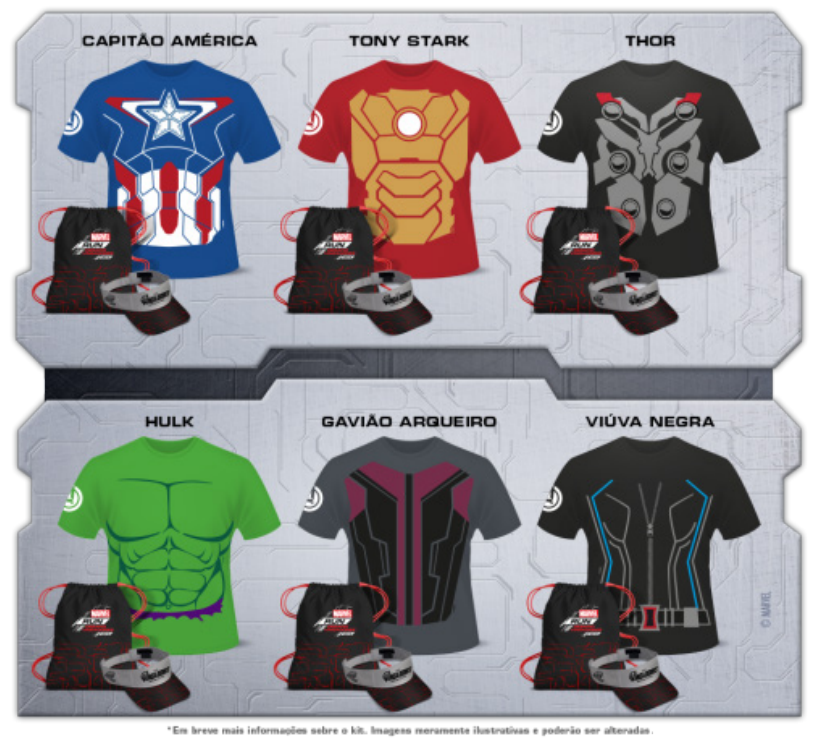

Figura 8 - Kit de participação dos super-heróis da Marvel Run: Desafio Vingadores 2015. Fonte: Blog Corrida de Rua, 2015.

Nota-se, portanto, que a direção de arte da Marvel Run atrelou métodos organizacionais com a temática imersiva do evento, utilizando conceitos do nível comportamental que colaboraram de modo significativo para a construção de uma experiência positiva e organizada para seus participantes.

\subsection{Reflexivo: Disney Princess Magical Run 2017}

A Disney Princess Magical Run 2017 aconteceu na manhã do dia 12 de março de 2017, próxima ao Jockey Club, zona oeste de São Paulo. A organização desse evento ficou a cargo da Norte Marketing Esportivo, com apoio da Corpore e da Disney. Teve cerca de 13 mil participantes em um percurso divido entre caminhada de $3 \mathrm{~km}$, para participantes de todas as idades, e corrida de $7 \mathrm{~km}$, para maiores de 16 anos. 0 evento era também para o público masculino, embora a direção de arte, a divulgação e a premiação fossem voltadas somente para o público feminino. 
A corrida foi utilizada como estratégia de divulgação do filme A Bela e a Fera $^{3}$, lançado no Brasil em 16 de março de 2017, sendo que grande parte da cenografia da corrida girava em torno dos personagens principais do filme e de outras personagens da franquia Disney Princesa ${ }^{\circledR}$, com seus reinos e universos já conhecidos pelo público.

Princesas fazem parte do universo lúdico da Disney desde o lançamento de seu primeiro longa-metragem, em 1937, Branca de Neve e os Sete Anões (LOPES, 2015). Desde então, a empresa vem expandindo seu universo com outras personagens, com diferentes características e que construíram relações afetivas, em seus filmes, com diversas pessoas ao redor do mundo. Segundo o Disney Institute (2011, apud KUO, 2015), a Disney tem como ideologia de trabalho algo intangivel, simbólico, e que vem trazendo a gerações encantamento e emoção em todos os seus trabalhos: a magia.

Só porque não é possivel atribuir um valor quantificável à magia não quer dizer que ela não exerça um papel poderoso na Disney e em outras empresas ao redor do mundo. Na verdade, é fácil ver os efeitos da magia nos negócios, particularmente em um lugar como o Walt Disney World. Basta observar os convidados. A criança que vê o Mickey pela primeira vez, em tamanho natural e pessoalmente [...] cada um desses é um momento mágico no qual o vínculo entre o cliente e a empresa é forjado e fortalecido.

Isso mostra que a Disney busca atuar no nível reflexivo para reafirmar seu compromisso de envolvimento e afetividade por meio de elementos simbólicos que integram seus personagens e suas histórias a seu público. A magia é, em outras palavras, a exaltação de memórias afetivas positivas que adultos tiveram quando crianças e que as crianças utilizarão como base de formação para a vida adulta.

Conforme relata a participante Juliana Vargas no blog Corre Mulherada,

\footnotetext{
${ }^{3}$ A Bela e a Fera (Beauty and the Beast) é um filme musical norte-americano de 2017, do gênero romance/fantasia, realizado por Bill Condon e escrito por Stephen Chbosky. É baseado na animação homônima de 1991, baseada no conto de fadas de Jeanne-Marie Leprince de Beaumont.
} 
eu sei que a maioria dessas princesas representa um modelo meio antiquado do que é ser mulher e tudo mais, mas não consigo conter um certo fascínio por esse universo, talvez por saudosismo da minha infância que foi marcada por filmes como A Pequena Sereia, A Bela e a Fera, Pocahontas, Mulan...

O saudosismo mostrado pela corredora reflete a forma como os elementos reflexivos são trabalhados pela direção de arte desse evento, buscando ativar memórias afetivas positivas nos participantes por meio de seus personagens e de suas histórias.

É importante notar como a Disney transporta essas experiências, por meio da direção de arte da cenografia, para a Princess Magical Run, criando uma corrida totalmente imersiva criando ambientes lúdicos com personagens de características marcantes para moldar uma experiência que vai além do ato de correr. É um evento em que os corredores reafirmam sua autoimagem de fãs desse universo, em que buscam espelhar suas características de identidade nas princesas Disney e em que essa temática imersiva diz muito sobre o que são e o que pretendem demonstrar ao mundo.

A reafirmação da autoimagem é refletida no depoimento de Juliana Vargas ao dizer que "eu também fui de semi-princesa, com coroa e saia de paetês". De fato, muitos participantes foram vistos trajando fantasias de princesas, o que reforça a característica de imersão reflexiva da corrida, em que os corredores assumiam o papel dos personagens da Disney por meio de vestuário, maquiagem e, muitas vezes, ações corporais, como visto na Figura 9.

A direção de arte do evento buscou criar cenografias viscerais e imersivas que, construíram uma experiência positiva e um ambiente lúdico aos participantes, de modo a ressaltar memórias afetivas. Um deles foram cabines na área de entretenimento do Jockey Club antes e depois da corrida, onde havia atrizes caracterizadas como princesas da Disney, cada uma em um cenário relativo a seu universo. Isso buscou tornar tangível, especialmente para as crianças, a experiência de vivenciar o universo lúdico das princesas Disney (Figura B.5). 


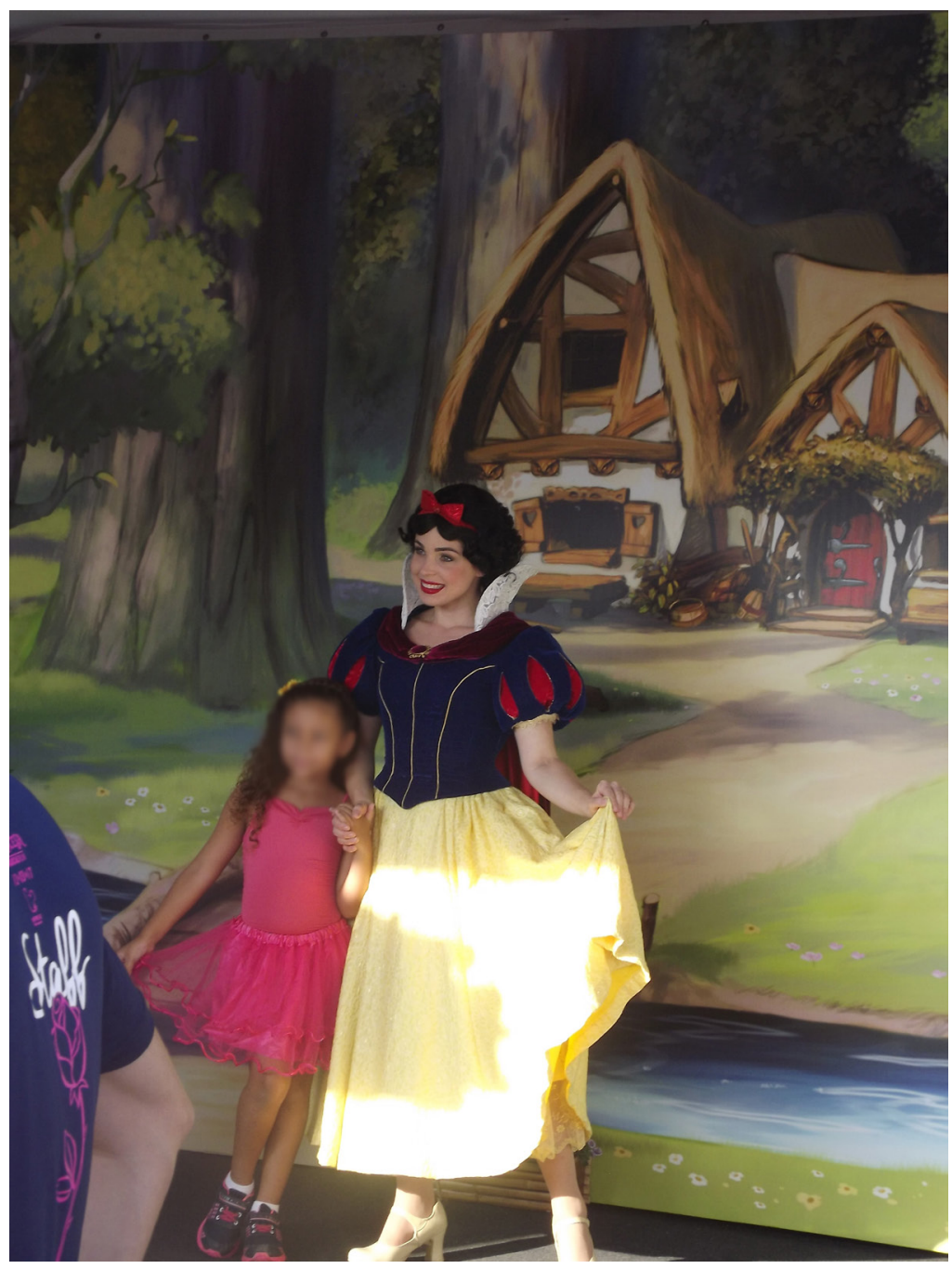

Figura 9 - Cabine com a princesa Branca de Neve na Princess Magical Run 2017. Fonte: acervo do autor.

Muitos desses cenários - tanto as cabines fechadas quantos as ao ar livre (Figuras B.2 e B.8) - foram elaborados pela direção de arte do evento para fazer aflorar lembranças positivas dos participantes e fazê-los lembrar de seu tempo de criança, enaltecendo um sentimento de nostalgia para os adultos. Já para as crianças, aquele era o momento para a construção do nível reflexivo com a marca Disney, de modo que, para as mais novas, a corrida apresentava mais aspectos viscerais que reflexivos. 
Outro ponto importante trabalhado pela direção de arte do evento foram os portais dispostos no percurso da corrida (Figura 10) e as placas motivacionais para os corredores (Figuras B.13 e B.14). Cada pórtico tinha a imagem de uma das princesas Disney, sendo que um deles chamou mais atenção por ser interativo. Como relata a corredora Juliana Vargas "também haviam [sic] pórticos temáticos - o que mais gostei foi o da Ariel, que soltava bolhas de sabão! Um toque de magia sempre é bem-vindo!".

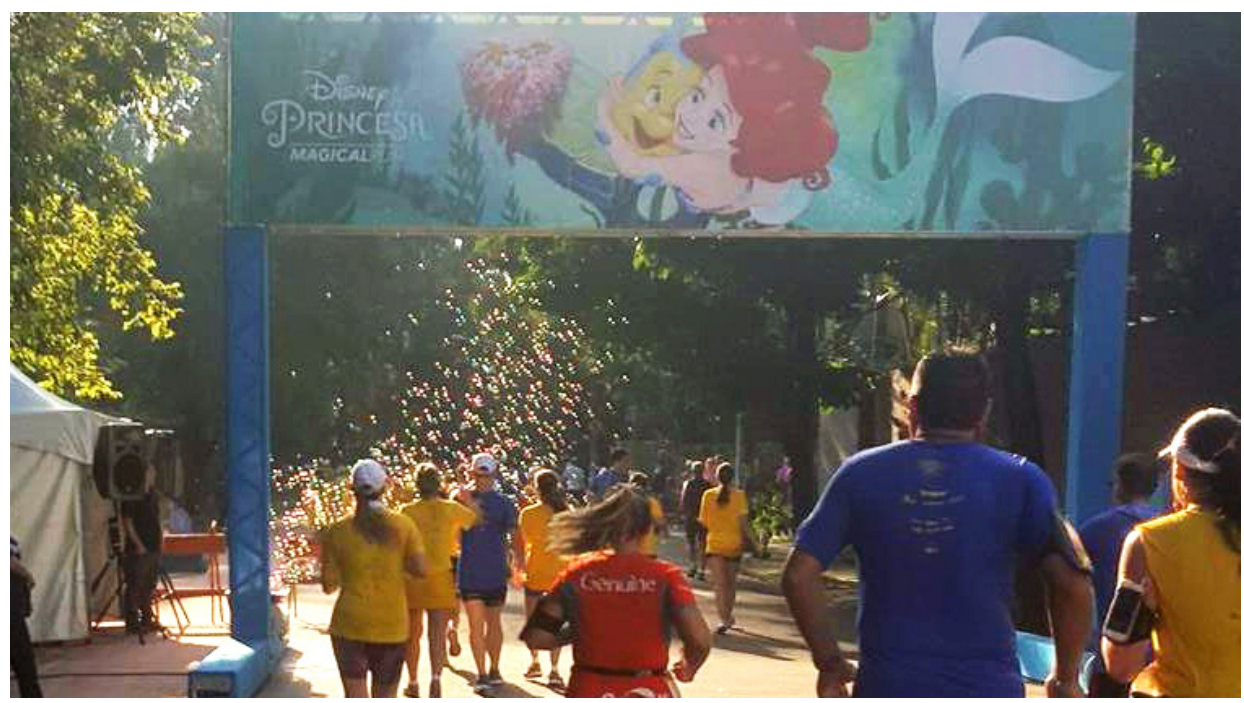

Figura 10 - Pórtico da personagem Ariel, princesa de A Pequena Sereia, soltando bolhas de sabão durante o percurso da Disney Princess Magical Run 2017. Fonte: Vargas, 2017.

A construção cenográfica em escala real, atrelada a músicas-tema das histórias, e os kits com medalhas no formato dos personagens, elementos criados com base no design reflexivo, tinham como objetivo proporcionar uma experiência amplificada do universo dos personagens Disney com a sua marca, além de uma interação afetuosa entre os corredores, trazendo à tona emoções duradouras. 